\title{
As Representações Sociais de portugueses sobre os imigrantes brasileiros no Youtube
}

\section{Social representations of Brazilian immigrants by the Portuguese on YouTube}

\author{
Luciane Moura Martins \\ Joseli Maria Silva \\ Universidade Estadual de Ponta Grossa
}

\begin{abstract}
Resumo: O artigo aborda as Representações Sociais sobre imigrantes brasileiros, construídas por portugueses, a partir do ambiente virtual Youtube. O crescimento recente da imigração brasileira em Portugal constitui novas relações sociais e conteúdos representacionais dispersos nos processos de comunicação. O Youtube foi a fonte de pesquisa em que foram analisados, por meio de análise de discurso, os significados presentes nas Representações Sociais veiculadas nos vídeos sobre a imigração brasileira, postados por portugueses, tomados como amostra. Os resultados evidenciam a significação elaborada pelos portugueses que associam os imigrantes brasileiros à ilegalidade e à exploração, ao mesmo tempo em que os vinculam a alegria, tropicalidade e sensualidade. Enfim, os conteúdos representacionais mesclam elementos de permanência e mudança que marcam as relações socioespaciais entre esses dois grupos sociais.
\end{abstract}

Palavras-chave: Representações sociais. Imigrantes brasileiros. Portugal. Youtube.

\begin{abstract}
The present paper highlights the social representations of Brazilian immigrants by the Portuguese on the virtual environment of YouTube. The recent growth of Brazilian immigration in Portugal establishes new social relations and representational contents scattered in the processes of communication. YouTube was the source of the research, in which the meanings of the social representations broadcasted in the sampled videos about Brazilian immigration posted by the Portuguese were investigated via discourse analysis. The results demonstrate the meanings formulated by the Portuguese, who associate Brazilian immigrants to illegality, exploitation, and at the same time to joy, tropicality and sensuality. Finally, the representational contents mingle elements of permanence and change that underline the socio-spatial relations between these two social groups.
\end{abstract}

Keywords: Social representations. Brazilian immigrants. Portugal. YouTube. 


\section{INTRODUÇÃO}

O objetivo do artigo é analisar as Representações Sociais sobre imigrantes brasileiros, construídas por portugueses, a partir do ambiente virtual Youtube ${ }^{1}$. A presença de brasileiros em Portugal é um fenômeno antigo e até mesmo naturalizado em função das relações coloniais e da identidade linguística cultural. Contudo, de acordo com Machado (2007), o perfil de brasileiros que constitui o movimento migratório tem se modificado intensamente, levando cientistas sociais portugueses a estabelecer uma divisão entre a velha e a nova imigração brasileira em Portugal.

O período contemporâneo, marcado pela globalização, possibilitou o aumento da mobilidade populacional de brasileiros em direção a muitos países do chamado mundo desenvolvido e Portugal foi um dos principais destinos. Os brasileiros, conforme dados do governo português, constituem o maior número de imigrantes no país. Esse fato intensifica os contatos socioespaciais entre esses dois grupos populacionais, construindo conteúdos representacionais que influenciam o perfil de relações entre eles.

Os conteúdos representacionais estão dispersos em todos os processos de comunicação e um dos ambientes mais importantes tem sido a internet. Por meio dela se difundem significados a partir de diferentes linguagens, tanto visual como escrita, que acabam compondo a vida social cotidiana, tal como argumentado por Castells (1999) sobre a cultura da virtualidade contemporânea. Jacques Lévy (1999) e Pierre Lévy (2001) afirmam que os meios eletrônicos são elementos que constituem os espaços e tempos das experiências vividas e assim produzem o conhecimento sobre o mundo, tal como também aponta Silva (2007).

${ }^{1}$ Disponível no endereço eletrônico www.youtube.com.
A internet é uma das mais importantes formas de comunicação no mundo contemporâneo, notadamente pela ideia de liberdade de expressão e de um certo anonimato dos usuários. Entre os mais populares ambientes virtuais está o site Youtube, que cria e dissemina Representações Sociais sobre inúmeros aspectos da realidade socioespacial através da ação de seus usuários. É no sentido de constituir uma importante fonte de acesso aos conteúdos de comunicação que ele se constitui no foco da busca de compreensão das Representações Sociais de portugueses sobre os imigrantes brasileiros ${ }^{2}$.

O site Youtube é uma ferramenta da internet, lançado oficialmente em 2005, que possibilita o compartilhamento de vídeos e, além disso, oferece a possibilidade de comunicação entre seus usuários. Esse ambiente virtual une em rede vinte e três países e está disponível em vinte e quatro idiomas diferentes. $\mathrm{O}$ site recebe aproximadamente duas horas de vídeos por minuto e ocupa a terceira posição entre os sites mais acessados do mundo ${ }^{3}$. Cada imagem postada permite aos usuários deixar o registro de suas impressões sobre elas, o que cria a possibilidade de debater os diferentes pontos de vista dos usuários provenientes de diferentes partes do mundo.

Como metodologia dessa pesquisa, primeiramente, foram utilizadas as seguintes palavras-chave para a busca no site Youtube "imigração brasileira em Portugal".

\footnotetext{
${ }^{2}$ Os ambientes virtuais, por meio dos quais as pessoas manifestam seus valores e ideias, são tão verdadeiros quanto os depoimentos (face to face). Nada garante ao pesquisador que os dados coletados por uma entrevista pessoal sejam mais ou menos verdadeiros do que os depoimentos coletados nos comentários postados no Youtube. Pelo contrário, o ambiente virtual permite maior liberdade de expressão, já que a interferência do pesquisador no momento do depoimento é nula. Nos ambientes digitais as pessoas e/ou personagens são mais autênticos nas expressões justamente por preservar determinada identidade e discursos frente à prática de pesquisa.

${ }^{3}$ Disponível em: http:/ / comunicarebrasilcom/2000inove/?p= 981. Acesso em 03/02/2011.
} 
Desse procedimento foram coletados 37 vídeos e um total de 1701 comentários postados por internautas no período de 1 de Agosto de 2006 a 30 de Setembro de 2010. Desse total, foram selecionados os vídeos de caráter institucional ${ }^{4}$ (agências governamentais, canais televisivos, Organizações não-governamentais), por acreditar que esses agentes sociais são capazes de congregar representações hegemônicas, já que exercem centralidade nas relações de poder no processo de comunicação social. Consideramos, para esse artigo, cujo foco está na representação produzida por portugueses ${ }^{5}$, os três vídeos postados por internautas de Portugal e que foram os mais acessados pelos usuários do Youtube. Os vídeos tomados como referência foram abordados a partir de técnicas de análise de conteúdo, considerando as frequências de evocação para a estruturação de eixos de interpretação.

Assim, na primeira seção realizamos uma discussão sobre o processo migratório de brasileiros para Portugal e as Representações Sociais como conceito de análise simbólica de relações espaciais. Na segunda seção são apresentados os resultados das representações construídas por meio da produção de vídeos.

\section{IMIGRAÇÃO BRASILEIRA, REPRESENTAÇÕES SOCIAIS E ESPAÇO}

Em suas reflexões sobre o espaço, Corrêa (1995) noz traz três elementos de análise: área, indivíduos e ações, concebidos a partir de distintas perspectivas teórico-

\footnotetext{
${ }^{4}$ Os vídeos caseiros, em geral, apresentam imagens de intimidade no interior das residências.

${ }^{5}$ Embora se reconheça a necessidade de explorar os vídeos postados por brasileiros, já que os comentários sobre eles envolvem depoimentos de portugueses, produzindo um campo representacional significativo, optou-se por restringir a amostra, pelo considerável volume de dados que será contemplado posteriormente, na elaboração da dissertação de mestrado.
}

-metodológicas e transformados ao longo da história do pensamento geográfico. $\mathrm{O}$ processo de imigração é um fenômeno que envolve todas as categorias propostas, já que envolve as ações de indivíduos, seus deslocamentos em busca de áreas que lhes propiciem condições de existência. Além disso, o fenômeno envolve mudança, transformação e relacionamentos entre grupos, tanto da sociedade receptora, como dos grupos que se deslocam.

O espaço, nessa perspectiva, tornase dinâmico, superando a perspectiva material, de suporte social, mas envolve também as relações entre as pessoas envolvidas nos processos. Massey (2008) argumenta que a ideia de dinâmica espacial implica em reconhecer a existência simultânea de outros, com suas próprias trajetórias históricas que se conectam e se desconectam, constituindo assim o espaço por meio das relações. A perspectiva de movimento constante também é trazida por Santos ao afirmar que "o espaço não pode ser apenas formado pelas coisas, os objetos geográficos, naturais e artificiais, cujo conjunto nos dá a Natureza. O espaço é tudo isso, mais a sociedade [...]". (SANTOS, 1985, p. 1).

Dentre as mais diversas vertentes teórico-metodológicas da abordagem espacial, a Geografia Cultural é aquela que tem considerado os aspectos subjetivos e relacionais do espaço que não é autônomo, pois, segundo Corrêa (2003), o espaço está vinculado aos processos da sociedade, sejam eles de qualquer natureza, inclusive o simbólico. Se a sociedade é uma teia de relações de pessoas em movimento constante, portanto imprevisível, o espaço é uma esfera de possibilidades, tal qual argumenta Massey (2008). O espaço, segundo a geógrafa

É uma dimensão implícita que molda nossas cosmologias estruturantes. Ele modula nossos entendimentos do mundo, nossas atitudes frente aos outros, nossa 
política. Afeta o modo como entendemos a globalização, como abordamos as cidades e desenvolvemos e praticamos um sentido de lugar. Se o tempo é a dimensão da mudança, então o espaço é a dimensão do social: da coexistência contemporânea (coetaneidade) ${ }^{6}$ de outros. (MASSEY, 2008, p. 15).

Nessa perspectiva, o espaço pode ser analisado a partir de significados e sentidos, e estes por sua vez pelas Representações Sociais, pois a realidade das pessoas representadas na vida cotidiana está permeada por símbolos.

As Representações Sociais são opiniões do senso comum que as pessoas constroem do mundo. Para Moscovici (1978), as Representações Sociais são entendidas como sendo teorias do senso comum, de grupos, que não são repetitivas, sendo constantemente transformadas, nas quais a construção dos conceitos se dá a partir de suas experiências de vida. As Representações Sociais são "uma modalidade de conhecimento particular que tem como função a elaboração de comportamentos e a comunicação entre indivíduos" (MOSCOVICI, 1978, p. 26).

A representação não é uma reprodução, e sim "uma reconstrução do dado em um contexto de valores, reações, regras e associações. Não se trata de meras opiniões, atitudes, mas de 'teorias' internalizadas que serviriam para organizar a realidade" (LEME, 1993, p.48). O espaço está imbricado, portanto, no processo representacional, constitui estruturas que fundam as Representações Sociais dos sujeitos, assim como o espaço se faz das Representações Sociais. Silva (2002), ao trabalhar com a relação entre espaço e Representações Sociais, considera que:

As Representações Sociais são dinâmicas, emergem como processo, pois são formadas pela sociedade que, simultaneamente, é

${ }^{6}$ Não constando do original. formada pelas representações. Os processos de ancoragem e objetivação que formam as Representações Sociais estão atrelados às estruturas históricas e sociais. Tais estruturas, ao mesmo tempo em que são construídas pela ação dos indivíduos, também os sujeita. (SILVA, 2002, p. 193).

As vivências de relações entre grupos de imigrantes e sociedades receptoras são permeadas pelas Representações Sociais, que por sua vez fundam suas práticas. No contexto das imigrações internacionais há especificidades a serem exploradas do ponto de vista de quem migra e da sociedade receptora. No caso da imigração de brasileiros para Portugal, é relevante argumentar que o passado colonial de relações entre Brasil e Portugal traz um universo representacional rico e constituído de elementos de identificação, mas também de conflitos.

De acordo com o Instituto de Estatística Nacional (INE) de Portugal ${ }^{7}$, os brasileiros constituem hoje o maior grupo de imigrantes em Portugal. Vivem em Portugal aproximadamente 116.000 brasileiros (aqueles com estatuto legal e com pedido de estatuto legal), ficam de fora dessa estatística os imigrantes com estatuto ilegal. O fluxo de brasileiros em direção a Portugal pode ser dividido em dois importantes momentos, segundo Machado (2007). Segundo o autor:

Num primeiro momento, a imigração brasileira assemelhava-se mais à imigração de europeus «do norte» (o que sempre significa « mais ricos »): ou seja, mais qualificada e posicionada em lugares mais altos nas hierarquias do mercado de trabalho ou, ao menos, era vista como estando entre a imigração rica europeia e a imigração pobre africana . Num segundo momento, estas características mudaram e a imigração brasileira caminhou cada vez mais a um assemelhamento às imigrações da África.

7 Disponível em: http://www.ine.pt/xportal/ xmain?xpid=INE\&xpgid=ine_main 
As qualificações são menores, os cargos ocupados no mercado de trabalho são os do «setor primário», as expectativas são menos promissoras e a integração é mais difícil. Não é por menos que as análises sobre essa população brasileira em Portugal têm tendido a dividi-la em duas fases, ou duas vagas : uma primeira mais rica e uma segunda mais pobre. Esta situação impõe outras novidades frente ao fenômeno da migração brasileira : a mudança gradual no perfil do imigrante ao mesmo tempo em que aumenta substancialmente o total da população brasileira em Portugal. Desde que surgiu e foi percebida nos anos 80, a população brasileira em Portugal esteve entre as mais significativas e importantes. Atualmente é o maior grupo de imigrantes mas, ao contrário da imigração do leste europeu, que parece arrefecer, a imigração brasileira não dá sinais de enfraquecimento de seus fluxos. (MACHADO, 2007, p. 2).

Para Malheiros (2007), a imigração brasileira dos anos oitenta e noventa esteve relacionada à conjuntura econômica desfavorável pela qual o Brasil passava nesta época:

A sucessão de crises económicas ${ }^{8}$ experimentadas pelo Brasil, nos anos 80 e 90, limitaram as oportunidades do mercado de trabalho e de mobilidade social, contribuindo para criar a pressão emigratória que levou os Brasileiros, não apenas para Portugal, mas também para outros países como o Japão, a Itália ou os EUA (...). Factores como a insegurança dos cidadãos ou a instabilidade dos mercados financeiros, associada a taxas de inflação muito elevadas em largos períodos dos anos 90, também contribuíram para incentivar o desejo de partida de muitos Brasileiros, sobretudo de classe média e mesmo média-alta. (MALHEIROS, 2007, p. 16).

O fim dos anos noventa do século $X X$ e o início do século XXI caracterizou-se também pela consolidação do processo de globalização que provocou a transformação das redes de imigração, como argumenta Padilla (2009)

(É) impossível hoje pensar no fenómeno ${ }^{9}$ da imigração estando desligado do processo mais amplo que define o presente: a globalização. (...) vemos que a globalização revela certos elementos importantes tais como: a) a mobilidade do capital e o investimento estrangeiro (Espanha e Portugal são grandes investidores na América Latina, ainda que também existam outros países europeus que efectuem investimentos estrangeiros na região), b) a facilidade dos transportes e a massificação e abaratamento do turismo (uma grande percentagem de imigrantes entram como turistas), c) a facilidade nas comunicações que mantém o globo conectado, d) a televisão permite saber quase instantaneamente o que acontece no resto do mundo, transmitindo de imediato as boas e as más notícias. (PADILLA, 2009, p. 29).

A atual presença de grupos de brasileiros em Portugal cria novos elementos que configuram relações socioespaciais específicas. Padilla (2004) argumenta que os imigrantes brasileiros que vivem em Portugal são significados por estereótipos relacionados à nacionalidade brasileira e posicionados em situações hierarquicamente inferiores às dos portugueses.

Assim, a nacionalidade constitui um importante elemento identitário na definição das fronteiras de convivência entre brasileiros e portugueses. Para Silva (2002), a noção de identidade "se constitui num instrumento que permite articular o indivíduo imigrante ao seu ambiente, possibilitando que o indivíduo (ou grupo) localize-se num sistema social e também seja localizado socialmente". (SILVA, 2002, p. 62). Cuche (1999), em sua reflexão, afirma que "a identidade é uma construção social (...) que se faz no interior de contextos sociais que determinam a

${ }^{8}$ Texto com grafia original de português de Portugal.

${ }^{9}$ Texto com grafia original de português de Portugal. 
posição dos agentes e por isso mesmo orientam suas representações e suas escolhas" (CUCHE, 1999, p.182).

A identidade torna-se uma construção da diferença entre os grupos "nós, portugueses" e "eles, brasileiros". Hall (1998) argumenta que os sentidos atribuídos à nação, por meio dos quais são construídas as identidades, estão presentes nas memórias que são resgatadas e a partir disso, são construídos os discursos.

Os discursos não se constituem apenas pelas linguagens falada e escrita, mas podem ser corpos discursivos, performances corporais impregnadas de simbologias do 'ser brasileiro' em Portugal. Além disso, o ser brasileiro ganha novas especificidades quando se observa que o conteúdo da imigração brasileira para Portugal vem sendo modificada em padrões de gênero. Segundo Padilha (2007):

Há pouco tempo, a imigração era pensada como um processo predominantemente masculino e, da perspectiva das políticas migratórias. (...) Em consequência, não podemos estudar as migrações sem considerar os aspectos claramente influenciados pelo género, desde o mercado laboral até às políticas migratórias. (PADILHA, 2007, p. 113).

$\mathrm{O}$ aumento do contingente feminino nos movimentos migratórios é um dado que complexifica a análise do fenômeno das Representações Sociais, pois homens e mulheres brasileiros desenvolvem diferentes experiências socioespaciais em território português, bem como a expressão do grupo de mulheres altera o conteúdo representacional sobre a imigração brasileira.

Enfim, a vivência espacial de brasileiros em Portugal confronta identidades por meio de processos de comunicação entre grupos, repleto de Representações Sociais de várias naturezas. Na próxima seção, são analisadas as Representações Sociais encontradas nos vídeos postados por portugueses no Youtube.

\section{REPRESENTAÇÕES SOCIAIS PRESENTES NOS VÍDEOS PRODUZIDOS POR PORTUGUESES SOBRE BRASILEIROS NO CONTEXTO DO YOUTUBE}

\section{O primeiro vídeo, intitulado 'Imigração} Brasileira em Portugal', desde a sua postagem em 31 de Julho de 2007 possui 16.710 exibições, sendo esse o mais acessado. $\mathrm{O}$ segundo vídeo com maior número de acesso é 'Mulher Brasileira em Portugal', com 7.897 exibições desde sua postagem em 18 de Setembro de 2009. O terceiro vídeo 'Costa da Caparica - Portugal' atingiu, desde a sua postagem em 11 de Setembro de 2009, um total de 7.108 exibições. Nesse sentido, os vídeos de maior acesso pelos usuários, selecionados pelas palavras-chave 'imigração brasileira em Portugal', possui uma tendência, a de associação da imigração brasileira, ligada à feminilidade e ao ambiente litorâneo.

O primeiro vídeo denominado 'Imigração Brasileira em Portugal' faz referência à imigração brasileira, não apenas ao fluxo migratório, mas também a aspectos sobre a comunidade brasileira em Portugal. O vídeo mostra a apresentação de um estudo realizado pela - ACIDI - Alto Comissariado para a Imigração e Diálogo Intercultural. De forma específica, esse vídeo foi o mais acessado e com um total de 23 evocações, possui as seguintes tendências: a centralidade nas evocações sobre o crescimento da imigração brasileira em Portugal e o desenvolvimento de estudos institucionais sobre a imigração, com $39 \%$ das evocações cada. As demais evocações fazem referência ao fluxo de Portugal em direção ao Brasil - associadas tanto ao fluxo migratório quanto ao fluxo econômico - e a relação econômica dos países e dos imigrantes somaram 9\% de evocações cada categoria. A última categoria presente no vídeo aborda aspectos relacionados ao vínculo 
que se estabelece entre Portugal e Brasil e somou $4 \%$ das evocações. Essas tendências presentes nas evocações podem ser vistas no gráfico abaixo:

Gráfico 1 - Vídeo Imigração Brasileira em Portugal.

\section{Vídeo - Imigração Brasileira em Portugal Evocações presentes no conteúdo do vídeo}

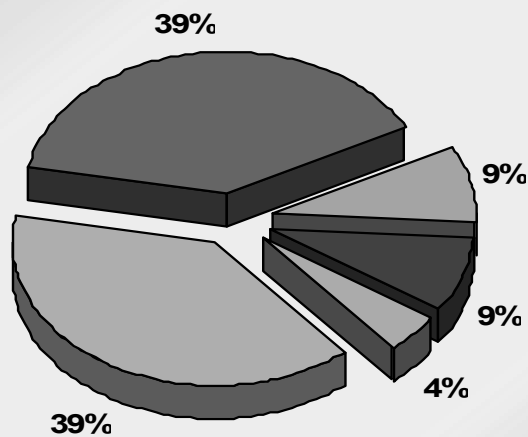

$\square$ Crescimento da imigração brasileira em Portugal $\square$ Desenvolvimento de estudos institucionais sobre a imigração $\square$ Fluxo Portugal em direção ao Brasil

$\square$ Relação econômica e financeira

$\square$ Vínculo afetivo entre Portugal e Brasil

Fonte: Vídeo do site Youtube, disponível em: http://www.youtube. $\mathrm{com} /$ watch? $\mathrm{v}=\mathrm{s} 1 \mathrm{ZYW} 6 \mathrm{yOZKA}$

Data de Postagem: 31 de Julho de 2007.

Org: Luciane Martins

As evocações relacionadas ao crescimento de imigrantes no país, segundo estudos da ACIDI (Alto Comissariado para a Imigração e Diálogo Intercultural) se dão porque o processo migratório de brasileiros/as para Portugal cresceu quase nove vezes entre 1986 e 2003, fazendo com que o tema se torne comum entre os portugueses. Os motivos para explicar essa crescente imigração estão relacionados primeiramente aos aspectos culturais de Brasil-Portugal, entre os quais idioma é o maior deles, pois a facilidade com a língua é uma quebra nas barreiras da comunicação entre imigrantes e nativos.

O segundo motivo é de ordem econômica, pois as oscilações na economia brasileira fez com que os brasileiros/as em busca de melhores condições de vida (inclui nessa categoria a busca por emprego) sejam atraídos por ofertas de empregos em Portugal. Para Cunha (2007), a mídia é uma das responsáveis por esse processo, segundo a autora, as divulgações em que se acentuavam as oportunidades de emprego e o crescimento acelerado da economia de Portugal, além do acolhimento dos 'irmãos de além-mar', são fatores determinantes nesses fluxos migratórios.

O crescente fluxo migratório de brasileiros/as para Portugal está despertando interesse de pessoas no desenvolvimento de estudos sobre a imigração, ora para explicar o fenômeno, ora para deixar em evidência essa relação Brasil-Portugal. a abordagem da imigração brasileira para Portugal vem ganhando proporção não só em estudos vinculados a instituições oficiais de Portugal ${ }^{10}$, mas também na academia.

Para o professor Jorge Malheiros para a realização desses estudos é fundamental contar com o apoio das instituições oficiais de Portugal ligadas à imigração, pois além de reunir as informações dispersas, é preciso explorar os aspectos não só abordados na academia, mas por políticos e pela população. O professor ainda afirma que é importante discutir e estudar todas as relações que envolvem Brasil e Portugal, não apenas as ligadas aos fluxos econômicos, visto que o fluxo de pessoas está crescendo de forma que não se consegue mais estudar apenas a economia, sem relacioná-la com a realidade da população, como pode ser visto no comentário abaixo:

Agora do ponto de vista mais profundo, porque o estudo? Porque relativamente à imigração brasileira para Portugal, nós sabíamos várias coisas, mas elas estavam

${ }^{10}$ INE - Instituto Nacional de Estatísticas de Portugal; SEF - Serviços de Estrangeiros e Fronteiras; ACIDI - Alto Comissariado para a Imigração e Diálogo Intercultural; OI - Observatório da Imigração. 
dispersas e misturadas às vezes com tratamentos de toda imigração, e nos outros casos estavam em teses de mestrados, ou em trabalhos de fim de curso e teses de mestrados e não eram conhecidas, estavam fechadas na academia.

(Professor Jorge Malheiros - retirado do vídeo Imigração Brasileira em Portugal).

O segundo vídeo 'Mulher Brasileira em Portugal' é o vídeo com maior número de evocações. A análise discursiva do vídeo foi dividida em 8 categorias, somando um total de 50 evocações. Como pode ser visto no gráfico 4 abaixo, a centralidade de duas categorias: as dificuldades encontradas por imigrantes brasileiros/as em Portugal com $50 \%$ das evocações, e a comparação entre as mulheres brasileiras e as mulheres portuguesas presentes em $20 \%$ das evocações. Em terceiro lugar, com $12 \%$ das evocações, aparecem as características positivas dos brasileiros. As demais categorias que não tiveram um número significativo de evocações são: com $10 \%$ das evocações, as Relações históricas entre Brasil e Portugal, com $2 \%$ das evocações cada estão as que fazem referências aos Imigrantes na Europa, aos Estudos científicos, ao fato de Valer a pena morar em Portugal e o Aumento da imigração brasileira.
Gráfico 2 - Vídeo Mulher Brasileira em Portugal.

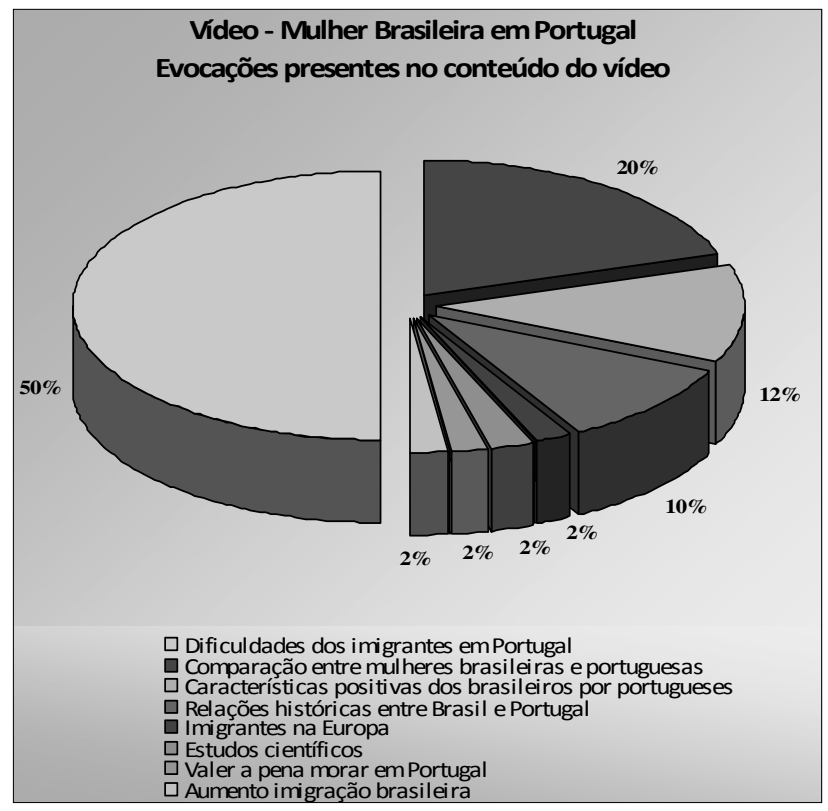

Fonte: Vídeo do site Youtube, disponível em: http:/ / www.youtube. $\mathrm{com} /$ watch? $\mathrm{v}=\mathrm{tCVq0}$ syU9CE

Data de Postagem: 31 de Julho de 2007.

Org: Luciane Martins

O ponto central desse vídeo são as dificuldades encontradas por imigrantes em Portugal, mas com uma análise mais avançada ${ }^{11}$ nesse $50 \%$ das evocações total do vídeo, vemos no gráfico 4 que dessas dificuldades, 92\% fazem referência ao preconceito e as demais ao desemprego e a saudade do Brasil, com $4 \%$ cada uma das categorias. Essa tendência também pode ser observada no comentário abaixo:

Quando chega aqui, o imigrante tem muitos pontos a seu favor, mas também vai sentir na pele o que realmente significa a palavra 'imigrante', desemprego, saudade de casa e até mesmo preconceito, são alguns dos desafios que o brasileiro enfrenta em terras lusas.

(Leda Barros - repórter - retirado do vídeo Mulher Brasileira em Portugal).

${ }^{11}$ A metodologia utilizada nesse vídeo é a mesma utilizada nos outros, porém de uma forma mais avançada, pois nas evocações referentes as dificuldades encontradas pelo imigrantes, notou-se várias evocações que poderiam ser classificadas em outras categorias possibilitando uma análise mais específica. 
Gráfico 3 - Vídeo Mulher Brasileira e Portugal

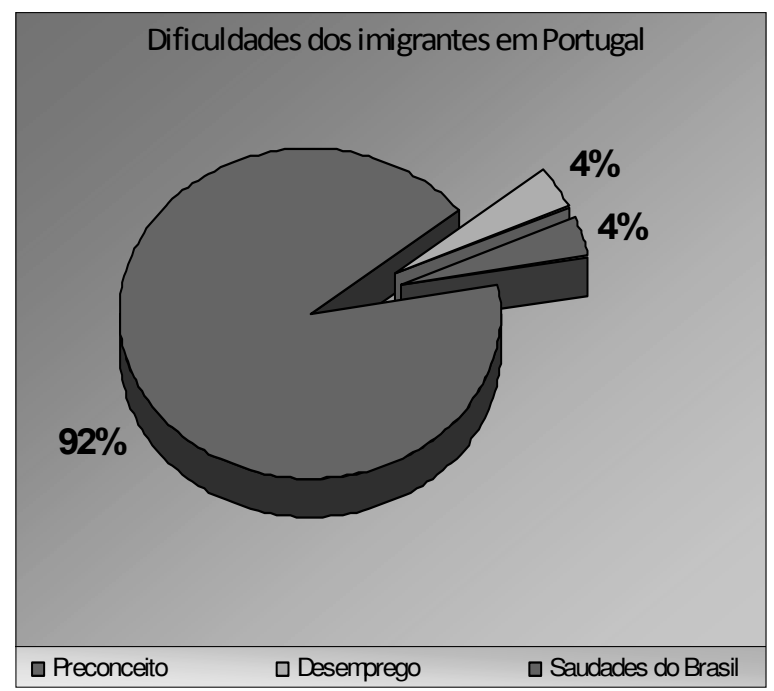

Fonte: Vídeo do site Youtube, disponível em: http://www.youtube. $\mathrm{com} /$ watch? $\mathrm{v}=\mathrm{tCVq0}$ syU9CE

Data de Postagem: 31 de Julho de 2007

Org: Luciane Martins

Filtrando os dados relacionados às dificuldades encontradas por imigrantes, percebemos que dos $92 \%$ relacionados ao preconceito (gráfico 4), vemos no gráfico 5 - abaixo, que $79 \%$ delas estão relacionadas à mulher brasileira, às suas características, aos seus trabalhos, mas sempre associadas à prostituição. $\mathrm{O}$ restante das evocações, $16 \%$ delas falaram da prostituição de forma isolada, apenas da dificuldade que é ser comparada a uma prostituta e $5 \%$ fazem referência ao casamento de brasileiras com portugueses.

\section{Gráfico 4 - Vídeo Mulher Brasileira em Portugal}

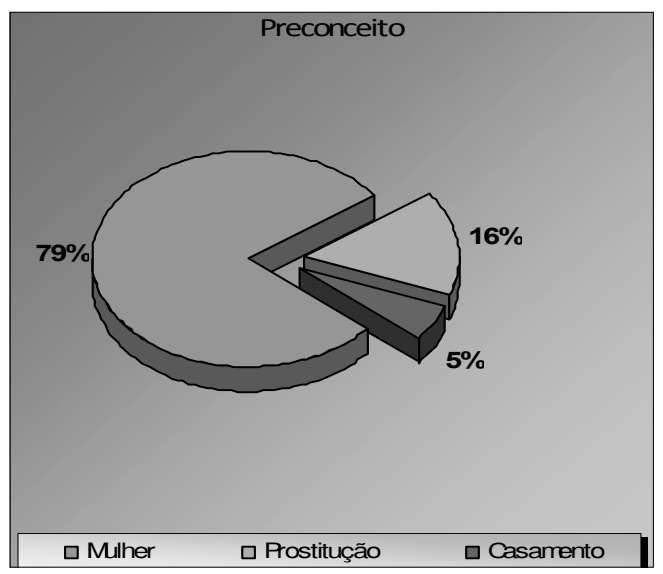

Fonte: Vídeo do site Youtube, disponível em: http:// www.youtube.com/watch? $\mathrm{v}=\mathrm{tCVq0}$ syU9CE

Data de Postagem: 31 de Julho de 2007.

Org: Luciane Martins
Ah!!!, o preconceito é muito grande, a associação da mulher, da imagem da mulher brasileira a prostituta ainda é muito forte, assim aqui em Portugal mais do que em outros países da Europa.

(Letícia Barros - retirado do vídeo Mulher Brasileira em Portugal)

Passei situações constrangedoras num trabalho que tive em um Casino de Lisboa, eu trabalhava no bar do Cassino e pessoas recusaram ser atendidas por mim porque eu era brasileira. Tem um caso de um amigo português, eu tenho muitos amigos portugueses e na véspera do casamento ligou, é... (pausa breve) foi constrangedor pra mim né, porque eu considerava um amigo e me chamou pra fazer uma despedida de solteiro com ele. É um preconceito? É preconceito, só que realmente as brasileiras que vem pra cá, a maior parte delas vem pra prostituição, vem pra... é arrumar casamento com portugueses.

(Lívia Costa e Silva - retirado do vídeo Mulher Brasileira em Portugal)

O preconceito sofrido pelas mulheres, muitas vezes relacionado à sua corporalidade, ora como prostitutas, ora como meio de conseguir um emprego ou casamento, sendo a prostituição o mais marcante. A imagem sensual e a situação econômica associada ao desemprego e a educação faz com que muitas mulheres optem pela prostituição. A atividade da prostituição não é crime, mas entendida pela sociedade com costumes tradicionais como algo imoral.

O crescente 'mercado do sexo' faz com que muitas mulheres imigrantes tenham duas formas de inserção nesse mercado, 'voluntária e forçada', a prostituição voluntária é desenvolvida pelas mulheres imigrantes ilegais e a forçada é quando essas mulheres são vítimas do tráfico de mulheres ou em alguns lugares também chamado de 'tráfico de seres humanos'. 
O estereótipo de prostituta quando se referem às mulheres brasileiras, segundo Cunha (2007), tem na mídia o principal difusor, através de propagandas, notícias e principalmente das imagens de telenovelas, como visto no comentário abaixo:

Ao longo destes trinta anos, homens e mulheres portugueses cresceram visualizando estórias, dramáticas e cómicas, contadas em português do Brasil, onde mulheres sensuais e homens viris lutavam por amor, poder e dinheiro. Nestas estórias muitas portuguesas, e portugueses, observaram outros modelos de família, sexualidade e sociabilidade. (CUNHA, 2007, p.10-11).

Essas imagens parecem ter reflexo no olhar coletivo de portugueses/as sobre as imigrantes brasileiras. A mídia é responsável por mostrar um estereótipo envolvendo as mulheres como uma mercadoria pronta para ser consumida num mundo em que o que prevalece é a hegemonia masculina. São esses pontos que fazem com que as mulheres imigrantes sejam todas classificadas ou comparadas às prostitutas.

Eles (portugueses ${ }^{12}$ ) têm um contato muito maior com a comunidade brasileira não só pelo contato direto né, mas toda, toda, toda a parte cultural que há tanto tempo a gente tem este intercâmbio principalmente através de telenovela e tudo mais, assim eles já podiam ter, ter mudado né, um bucado este imaginário né, mas na verdade a mídia ajuda a construir um bucado este imaginário perverso, então pode ver que todo jornal assim associa a imagem do brasileiro, ou é traficante ou é bandido, prostitua, então é, as pessoas tem isto mesmo muito forte dentro delas né.

(Letícia Barros- - retirado do vídeo Mulher Brasileira em Portugal)

Outro ponto que fez com que os portugueses tenham essa imagem negativa das mulheres brasileiras é um movimento

${ }^{12}$ Não constando do original. chamado 'Mães de Bragança'. Esse movimento encabeçado pelas mulheres (esposas traídas) da cidade de Bragança em Portugal que queriam começar uma guerra contra as chamadas 'Meninas do Brasil' para acabar com a prostituição na cidade.

Apesar de todas as dificuldades enfrentadas pelos brasileiros/as em Portugal, há quem diga que vale a pena morar no país, desde que se diferencie desse imaginário que os portugueses montam sobre os brasileiros/as, como visto no comentário da brasileira que reside há três anos em Portugal:

Vale a pena a partir do momento que você (pausa breve) faça a diferença e mostre que você não é este todo, que você não faz parte da farinha do mesmo saco.

(Lívia Costa e Silva - retirado do vídeo Mulher Brasileira em Portugal).

Outra categoria central nesse vídeo é a relação de comparação entre mulher brasileira e mulher portuguesa presentes a partir do questionamento da repórter sobre o que realmente os portugueses acham das mulheres brasileiras, somando um total de $20 \%$ das evocações presentes no vídeo (Gráfico 4). As mulheres brasileiras imigrantes além das características comuns a todos os brasileiros/as apresentam uma imagem muito exotizada pelos portugueses/as, e na muitas vezes são comparadas às portuguesas, pois as mulheres brasileiras são consideradas como mais charmosas, que dão mais importância para o corpo, e que muitas vezes utilizam o corpo de forma apelativa para conseguir trabalho ou casamento, como constatado no comentário abaixo:

$\mathrm{O}$ que eu posso encontrar de diferente na mulher brasileira da mulher portuguesa? Talvez mais...é, é charmosa, tem um caráter mais charmosa, em termos de... pronto... dão muita importância a cultura de imagem 
e isto obviamente que é..., se traduz em uma beleza mais apelativa talvez do que mulher portuguesa. (pausa) Mulher brasileira..., Deus criou a mulher e distribuiu a beleza como sabe que a tornou única, é, morena, olhos bonitos, é, charmosa, agora se me disser que ela não quis usar o que tem a seu favor (fazendo referência ao corpo ${ }^{13}$ )... (pausa) eu talvez não tivesse abordado.

(Roberto Santos (comerciante português) - retirado do vídeo Mulher Brasileira em Portugal).

A imagem de brasilidade tem um efeito maior sobre as mulheres, pois carregam consigo não só características como a alegria, a simpatia e a cordialidade, mas têm seu corpo como uma 'marca brasileira'. São características físicas que as destacam entre as portuguesas e que por muitas vezes são obrigadas a disfarçar ou a transformar seu corpo para não sofrer com tanto preconceito, pois são consideradas "mulheres fáceis", segundo Padilla (2007).

O terceiro vídeo 'Costa da Caparica-Portugal' mostra como central, com 30\% das evocações, a presença de imigrantes brasileiros/as, com $24 \%$ das evocações, a associação das paisagens litorâneas de Portugal com o Brasil, com 17\% das evocações, as características dos brasileiros e com $14 \%$ das evocações totais do vídeo, a presença da música e da cultura brasileira. As demais categorias ficaram abaixo de $10 \%$ das evocações cada.
Gráfico 5 - Vídeo Costa da Caparica - Portugal

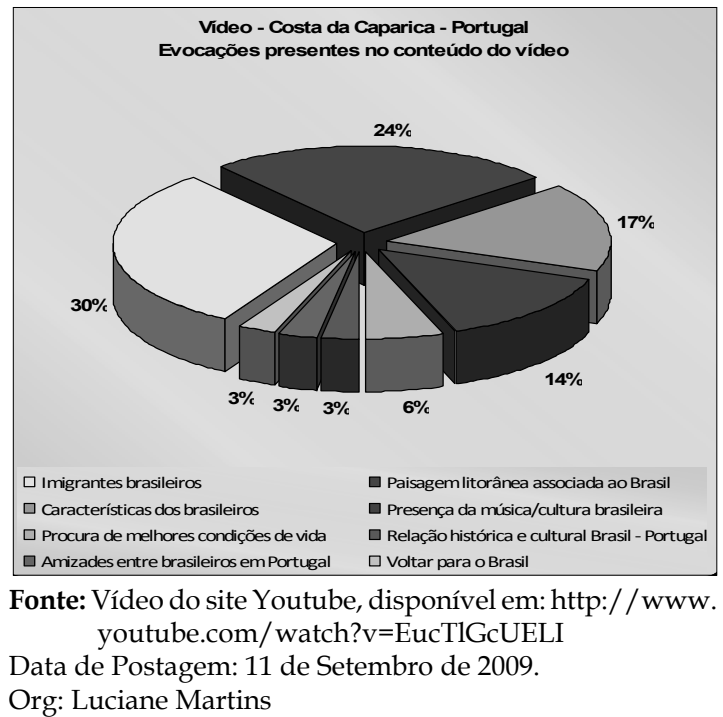

A centralidade do vídeo na presença de imigrantes brasileiros/as em Portugal e a associação da paisagem portuguesa ao Brasil está na forma com que os brasileiros/ as se relacionam com os portugueses/as, pois a facilidade com a língua auxilia a vivência desses imigrantes em território português, fazendo com que ele/a crie suas espacialidades. Nesse sentido, os lugares acabam por ter uma representatividade no cotidiano das pessoas. Muitos desses lugares ocupados por grande número de imigrantes brasileiros/as, faz com que a espacialidade desse lugar seja construída a partir das características dos brasileiros / as como pode ser viso nos comentários abaixo:

Aproveitando o calor decidimos ir até a costa e conferir este cantinho luso-brasileiro. Para curtir o visual fomos pela Ponte 25 de Abril, ao nosso lado o cristo de braços abertos sob o Tejo, parece o nosso Cristo Redentor, mas este aí é o Cristo Rei “o português", algum engarrafamento e chegamos. Sol, praia, até parece o Brasil.

(Leda Barros - repórter - retirado do vídeo Costa da Caparica-Portugal).

\footnotetext{
${ }^{13}$ Não constando do original.
} 
Trabalhar na Costa é muito gratificante sabe, a gente (pausa breve) encontra as colônias de brasileiros né, muitos brasileiros que ficam aqui, vem e a energia boa, vem se divertir, anima. Toda festa é alegria, só alegria. Todos os sítios né, todos os locais que eu já me apresentei, a Costa da Caparica é onde eu encontro mais número de de público né, muito brasileiro na costa, muito.

(Músico - Roberto Armani - retirado do vídeo Costa da Caparica- Portugal).

A representatividade das festas, das danças e das músicas brasileiras é muito forte em Portugal. Alguns bares tocam músicas brasileiras para atrair clientes, como pode ser visto no comentário abaixo:

Eu gosto de um ambiente que me proporcione vender e um ambiente que proporcione vender tem haver também com o Brasil, com festa, com samba, com forró.

(Pedro Monteiro - proprietário de um bar - retirado do vídeo Costa da Caparica Portugal).

Os portugueses associam os brasileiros à festa, ao samba, características essas relacionadas à alegria e à diversão e que deixam os imigrantes brasileiros/as em evidência no país, pode ser decisiva na hora de arrumar emprego. Os brasileiros/ as apresentam uma imagem de alegria, a simpatia, e a cordialidade que são características esperadas de brasileiros/as, portanto, são mais adequados nas profissões que tenham tratamento com os clientes, como garçons, músicos, vendedores de loja, etc.

Essa relação com o mercado de trabalho desenvolve a construção de identidades, que nesse caso são imagens estereotipadas do Brasil. Portanto, os brasileiros/as além do seu estereótipo (brasilidade), têm que se submeter ao processo de exotização, ou seja, devem se adaptar aos estereótipos portugueses. Machado (2008, p. 703) nos diz:
Chamo de "exotização" esse processo de relação complexa de um grupo social com as representações simbólicas a que estão sujeitos, envolvendo representação e ação. Assim, no caso dos brasileiros em Portugal, adaptar-se mais eficientemente aos estereótipos portugueses podia conferir maior poder a determinadas pessoas, que impuseram a sua própria forma de brasilidade. A imagem portuguesa da "brasilidade" se apresentava ampla e vazia o suficiente para abarcar qualquer um que não fugisse dos estereótipos de malandragem, hipersexualidade e alegria. A forma com que essas características amplas foram - e continuam sendo elaboradas é que variava conforme a origem e o universo cultural do intermediador em questão. (MACHADO, 2008, p. 703).

A análise de conteúdo que envolveu o discurso presente nos três vídeos tomados como amostra para este texto, possui um total de 109 evocações, apresentando uma centralidade em torno das dificuldades encontradas pelos brasileiros que vivem em situação de imigrantes, sobretudo como ilegais em Portugal, com $25 \%$ das evocações. Com a mesma centralidade, aparecem as características positivas sobre o povo brasileiro, sobretudo quando se trata das mulheres. Essa tendência discursiva evidencia o peso das mulheres na construção das Representações Sociais da imigração brasileira em Portugal. Em terceiro lugar, o crescimento da imigração brasileira em Portugal, com $20 \%$ das evocações. Dentre elas, a associação de paisagens litorânea com o Brasil somam $9 \%$. O vínculo histórico/cultural e afetivo entre Portugal e Brasil apareceu em $8 \%$. As demais evocações, como pode ser visto no gráfico abaixo foram dispersas e estão representadas como: a 'Relação econômica e financeira' entre Brasil e Portugal com $4 \%$ e na categoria 'Outros', com uma totalidade de $3 \%$, se enquadra as categorias 'Amizades entre brasileiros em Portugal, 
Valer a pena morar em Portugal e o Fluxo de Portugal em direção ao Brasil', como pode ser visto no gráfico abaixo:

Gráfico 6 - Síntese linguística dos vídeos.

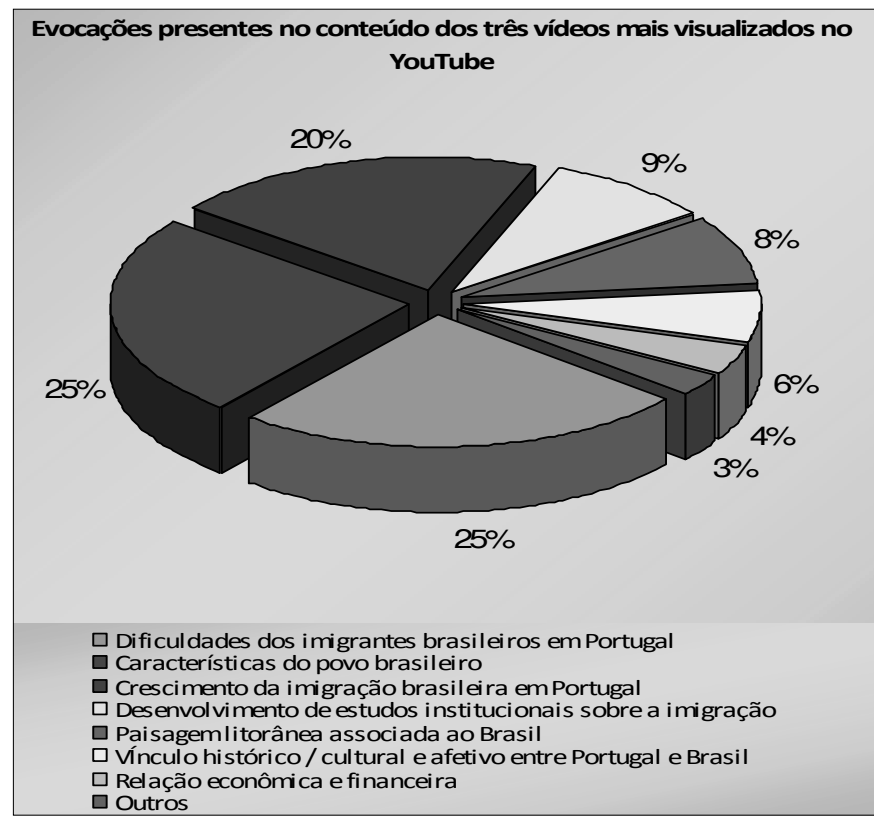

Fonte: Vídeos do site Youtube, disponível em: http:/ / www.youtube.com Org: Martins

É comum nas Representações Sociais presentes nos três vídeos uma imagem brasileira de povo alegre, simpático, do o Brasil como um país de mulheres bonitas, que se apresentam de forma sensual. Essas características estão associadas à praia, ao sol, à tropicalidade que os brasileiros refletem. Uma análise mais específica, por vídeo, revela as Representações Sociais que dão maior sentido à análise geral.

Contudo, conforme Machado (2008), a população imigrante brasileira não é um receptáculo de estereótipos, mas são seus produtores ativos, utilizando-se da brasilidade para a conquista de postos de trabalho e de um lugar no universo simbólico português.

\section{CONSIDERAÇÕES FINAIS}

O presente texto abordou a estruturação da imagem do Brasil a partir de uma análise linguística de vídeos postados por portugueses no site Youtube. Para tanto, desenvolvemos uma discussão acerca do espaço de modo a compreender como este é analisado a partir dos significados e dos sentidos que nos levam à construção das Representações Sociais. Os símbolos que envolvem o cotidiano das pessoas são fundamentais para construir um caminho nesse processo de produção de sentidos, em que as ações e principalmente as linguagens são focos centrais dessa produção. Essa produção de sentidos no cotidiano tem como início a linguagem, meio pelo qual as pessoas que produzem os sentidos se posicionam em relações sociais cotidianas. Esses elementos podem explicar a formação das Representações Sociais, mas nem todos possuem a mesma importância.

$\mathrm{Na}$ análise linguística dos vídeos, foi evidenciado que as Representações Sociais se materializam na produção simbólica a partir das evocações, pois, após o momento da postagem do vídeo, a informação torna-se real e passa a fazer parte da realidade socioespacial cotidiana. As Representações Sociais produzidas são fundamentais nesse momento para construirmos uma imagem do Brasil a partir das espacialidades construídas pelos brasileiros/as em Portugal e expostas nos vídeos do Youtube.

Dos três vídeos de maior expressão postados por portugueses no Youtube, o que se refere exclusivamente às mulheres é o segundo mais exibido, e é o que traz como elemento importante a influência da corporalidade feminina na formação da imagem do Brasil em Portugal. A mulher brasileira carrega em seu corpo uma marca que simboliza o Brasil, que são características associadas não apenas aos comportamentos, mas também à aparência 
física. As características de simpatia, alegria, associadas à beleza e à sensualidade, possibilitam às brasileiras a obtenção de vantagens financeiras nas atividades de prostituição.

As representações construídas sobre brasileiros por portugueses estão presentes nas relações cotidianas de ambos, já que as representações servem de referências para o agir na vida diária e conduzem aos lugares sociais, hierarquias, alianças e disputas. Enfim, é do encontro dessas complexidades que se instituem as espacialidades vividas por brasileiros em Portugal.

\section{REFERÊNCIAS}

CASTELLS, M. A Sociedade em Rede. São Paulo: Paz e Terra, 1999.

CORRÊA, R. L. Espaço: um conceito-chave da Geografia. IN: CASTRO, I. E. de; GOMES, P. C. da C. e CORREAA, R. L. (Orgs) Geografia: conceitos e temas. Rio de Janeiro: Bertrand Brasil, 1995, p. 15-48.

2003.

O Espaço Urbano. São Paulo: Ática,

CUCHE, Denys. A noção de cultura nas ciências sociais. Bauru: EDUSC, 1999.

CUNHA, I. F. As telenovelas brasileiras em Portugal: indicadores de aceitação e mudança. Revista Trajectos, Lisboa, 2007.

HALL, S. A identidade cultural na pósmodernidade. Rio de Janeiro: DP\&A., 1998.

LEME, M. A. V. O impacto da teoria das Representações Sociais. In: SPINK, M. J. (org.). O conhecimento no cotidiano. As Representações Sociais na perspectiva da psicologia social. São Paulo: Brasiliense, 1993.

LÉVY, J. Os novos espaços da mobilidade. Geographia, Rio de Janeiro: UFF/EGG, ano 3, n. 6, 2002

LÉVY, P. O que é o Virtual? São Paulo: 34, 2001.

MACHADO, I. J. de R. Reflexões sobre a imigração brasileira em Portugal. Novo mundo, mundos novos. 2007. p. 1-11. Disponível em: http:// nuevomundo.revues.org/5889. Acesso em: 03/02/2011.

Sobre os processos de exotização na imigração internacional brasileira. Revista de Antropologia. São Paulo, USP, v. 51, n. 2, 2008.

MALHEIROS, J. Os brasileiros em Portugal - a síntese do que sabemos. IN: Imigração Brasileira em Portugal. MALHEIROS, Jorge (Org), Lisboa: Paulinas Editora. Junho/2007.

MASSEY, D. B. Pelo Espaço: Uma nova Política da Espacialidade; Tradução Hilda Pareto Maciel, Rogério Haesbaert. Rio de Janeiro: Bertrand Brasil, 2008.

MOSCOVICI, S. A representação social da psicanálise. Rio de Janeiro: Zahar, 1978.

PADILLA, B. Redes sociales de los brasileros recién llegados a Portugal: solidariedad étnica o empatia étnica?", comunicação apresentada à Conferência "Los Latinos al descubrimiento de Europa. Nuevas emigraciones y espacios para la ciudadanía. Génova, 2004 (publicado em SOCIUS Working Papers, ISEG/UTL, n. 2/2005).

SANTOS, M. Espaço e método. São Paulo: Nobel, 1985.

SILVA, G. S. da. Locale digital: (re) construindo no ciberespaço as identidades territoriais da migração brasileira. Dissertação - Geografia, 277f. Universidade Federal de Santa Maria - RS, 2007.

SILVA, J. M. A verticalização de Guarapuava (PR) e suas Representações Sociais. Tese - Geografia. 322f. Universidade Federal do Rio de Janeiro. PPGG, Rio de Janeiro. 2002.

Vídeo - Imigração Brasileira m Portugal. Acesso em Agosto de 2010. Disponível em: http:/ / www. youtube.com/watch?v=s1ZYW6yOZKA

Vídeo - Mulher Brasileira e Portugal. Acessado em: Agosto de 2010. Disponível em: http:/ / www. youtube.com/watch?v=tCVq0syU9CE

Vídeo - Costa da Caparica - Portugal. Acesso em: Agosto de 2010. Disponível em: http://www. youtube.com/watch?v=EucTlGcUELI

Recebido em: 03/05/11 Aceito em: 29/07/11 